\title{
Modelling the Behaviour of Large Gravity Wharf Structure under the effects of earthquake-induced liquefaction
}

\author{
Gopal S P Madabhushi*+, Jad I Boksmati* and Samy G Torres* \\ +Corresponding author \\ * Department of Engineering, University of Cambridge, Cambridge UK
}

\begin{abstract}
Gravity Wharf Structures are widely used worldwide to form shallow and deep water ports. They are large structures with a height of 25 50 m depending on the water depth. When these structures are to be sited on loose to medium dense sand, earthquake induced liquefaction settlements present a significant risk. This often requires expensive soil replacement or other ground improvement techniques. In this paper, the dynamic behaviour of these large structures that exert very high bearing pressures on the foundation soil was investigated for the first time. The level of settlements they can suffer due to soil liquefaction was investigated using dynamic centrifuge testing. It will be shown that the full liquefaction does not occur below the structure even when the free field soil fully liquefies during strong earthquakes. However there will be some stiffness degradation owing to excess pore pressure generation and consequent structural settlements. The level of these settlements are considered to be acceptable from a Service Limit State (SLS) perspective. In addition to this the hydro-dynamic pressures that act on the Gravity Wharf structure were also investigated.
\end{abstract}

Keywords: centrifuge modelling, earthquakes, liquefaction, settlement, wharfs

\section{Introduction}

In recent years there has been a surge in the construction of Ports and Harbours around the world to cater for the increased shipping traffic and to accommodate larger shipping vessels that are coming into operation. Many established ports such as the Port of Los Angeles, Dubai Port, Kandla and Visakhapatnam Ports in India etc. are upgrading to accommodate the increased traffic while new ports are being designed such as the Port of Nador, Morocco. Many of these ports are located in seismically active regions and therefore their design should include earthquake loading. Some of the ports are also located close to the estuaries of inland rivers or on old river beds that have loose, alluvial deposits. This brings in additional challenges to the earthquake resistant design of the port structures as saturated, loose alluvial deposits are vulnerable to liquefaction.

Gravity Wharf Structures are gaining popularity especially for creating break waters or expanding the existing berths in ports. They are easy to construct in a dry dock and can be towed to the desired location before sinking them by pumping in bulk material. The bulk material can be dredged sand from the seabed or dumped rock fill. They can be modular so that individual units are towed into location and sunk and then the tops can be held together with tie rods and capping slabs. The typical crosssection of a Gravity Wharf Structure is shown in Fig. 1. These can be very large structures with a height above the sea bed of $25 \sim 50 \mathrm{~m}$ depending on the water depth at the site and anticipated wave heights and a width of $25 \sim 30 \mathrm{~m}$ depending on the facilities required on the top to unload ships such as crane structures, temporary storage facilities etc. The length of these structures depends on requirement of simultaneous berthing of ships, ship sizes anticipated at the port, proximity to the shoreline etc. and can normally run to several hundred meters.

The Gravity Wharf Structures are normally placed on the seabed that has been levelled. In many locations worldwide there can be loose sand deposits that extend to $5 \sim 10 \mathrm{~m}$ below seabed, especially if the site is close to an existing or an old river bed. There may be bedrock, dense sand or stiff clay below this level all of which do not pose risk of liquefaction. It is well known that loose sand deposits 
can liquefy i.e. produce excess pore water pressures leading to a decrease in effective stress when subjected to earthquake loading. However, the Gravity Wharf Structures are quite heavy once they are filled with the bulk material and therefore apply quite a large bearing pressure on the sea bed that may be in the range of $250 \sim 500 \mathrm{kPa}$. It is not clear whether the foundation soil below such Gravity Wharf Structures can still liquefy in the presence of such large confining stresses. Further the main design concern for these structures is the magnitude of settlement they can suffer following an earthquake.

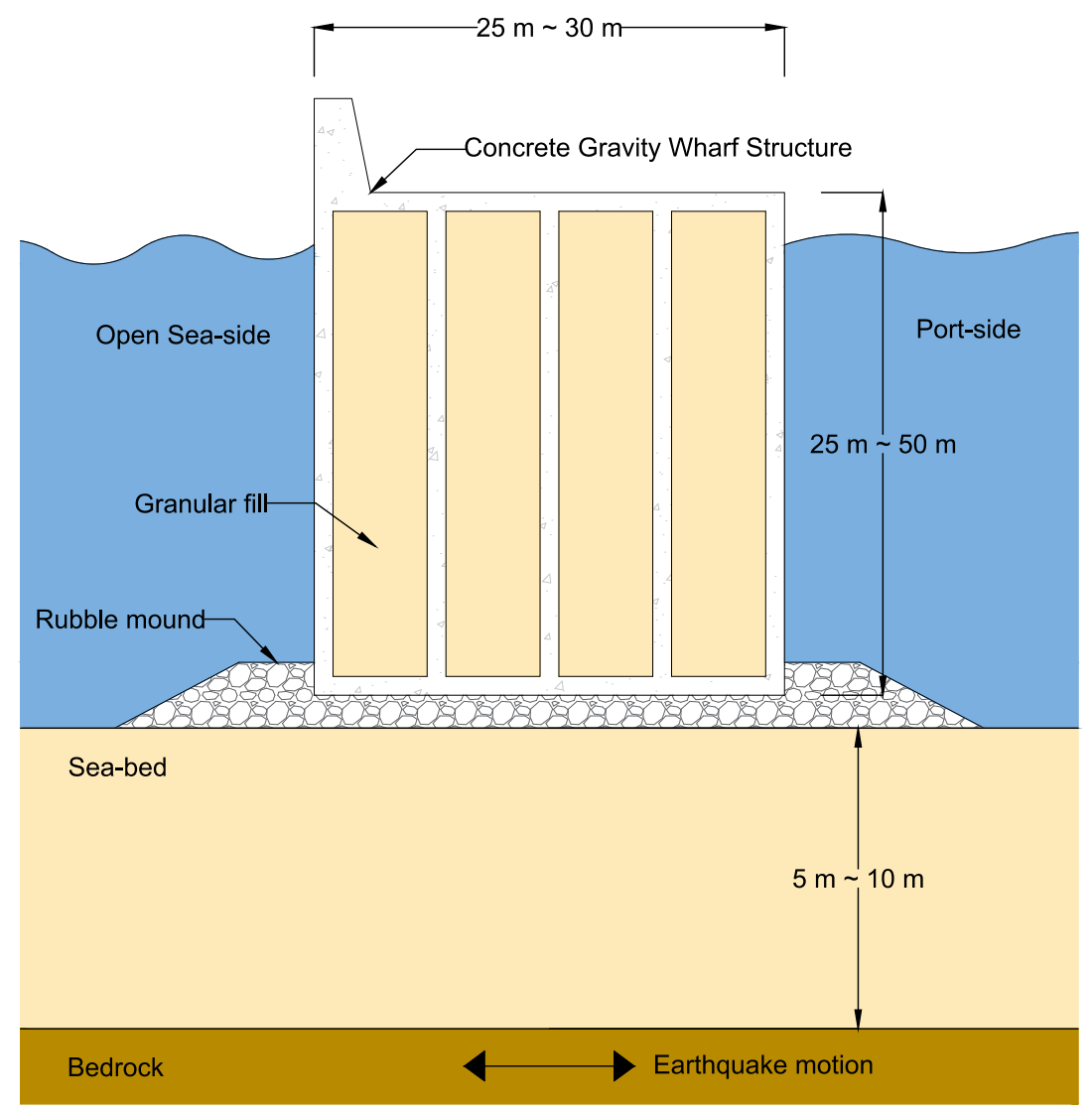

Figure 1: Schematic diagram of a typical cross-section of a Gravity Wharf Structure

In this paper the results from high gravity centrifuge testing on Gravity Wharf Structures will be presented and the excess pore pressures generated below such structures will be compared to the free-field excess pore pressures. In addition to these the dynamic response of the Gravity Wharf Structure and the hydro-dynamic pressures acting on either side of it will be considered. The settlements suffered by such structures during a series of earthquakes will also be presented. The main objective of this paper is to demonstrate the use of dynamic centrifuge modelling to investigate the behaviour of such large structures.

\section{Centrifuge Modelling}

Centrifuge modelling involves testing of reduced scale physical models in the enhanced gravity field of a geotechnical centrifuge. For materials with highly non-linear stress-strain behaviour, it is imperative that physical models are tested under prototype stress and strain levels. This can be achieved in a geotechnical centrifuge (Madabhushi, 2014). Centrifuge modelling is now considered as a valuable tool to study complex problems in Geomechanics. A well-established set of scaling laws 
shown in Table 1 exist that link the observed model behaviour at high gravities to that of the prototype structure in the field, Madabhushi (2014), assuming the same pore fluid in the model and prototype. It has been successfully used to study the problems of the seabed, Acosta et al (2016) who investigated hydroplaning in submarine slopes using centrifuge modelling, Qi et al (2016) who looked at the scour effects on the $p-y$ response of embedded piles. It is also possible to apply powerful earthquake loading to the centrifuge models inflight. Inagaki et al (1996) reported the damage to the caisson type quay walls at the Kobe port during the Hyogoken-Nambu earthquake. This triggered a flurry of research in Japan on sea-front structures subjected to earthquake loading. Testing of large sea-front caisson type structures was carried out earlier by Kawai et al (1998) who investigated the seismic performance of a caisson type seawall placed on an armoured embankment with a backfill behind the seawall. The prototype height of the caisson was about $6 \mathrm{~m}$, which is considered to be $1 / 4^{\text {th }}$ scale of the actual field structure, in other words the field structure is too large to be modelled in the centrifuge. Fujiwara et al (1998) studied a similar structure in which the soil below the rubble mound was replaced by denser material to avoid liquefaction induced settlements. Again the height of the caisson was about $4.85 \mathrm{~m}$. Satoh et al (1998) also studied the deformations of a caisson type quay wall that were induced by the backfill. Kamon et al (1998) investigated the reduction of settlements and rotations of the caisson type quay walls by replacing the foundation soil with denser material. The main objective of these studies was to investigate the settlement due to foundation soil's stiffness degradation and rotation driven by the backfill material during earthquake loading. However there are very few studies in which tall quay walls were studied that are more than $25 \mathrm{~m}$ long due to modelling difficulties i.e. the requirement to conduct a very high gravity centrifuge test to simulate such heights.

Table 1: Scaling Laws

\begin{tabular}{|c|c|c|}
\hline & Parameter & $\begin{array}{c}\text { Scaling Law } \\
\text { Model/Prototype }\end{array}$ \\
\hline \multirow{11}{*}{ 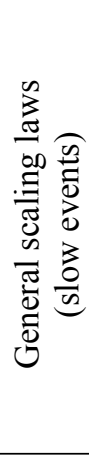 } & Length & $1 / \mathrm{N}$ \\
\hline & Area & $1 / \mathrm{N}^{2}$ \\
\hline & Volume & $1 / \mathrm{N}^{3}$ \\
\hline & Mass & $1 / N^{3}$ \\
\hline & Stress & 1 \\
\hline & Strain & 1 \\
\hline & Force & $1 / N^{2}$ \\
\hline & Work & $1 / \mathrm{N}^{3}$ \\
\hline & Energy & $1 / \mathrm{N}^{3}$ \\
\hline & Seepage velocity & $\mathrm{N}$ \\
\hline & Time (Consolidation) & $1 / \mathrm{N}^{2}$ \\
\hline \multirow{6}{*}{ 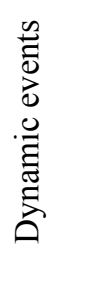 } & Time (Dynamic) & $1 / \mathrm{N}$ \\
\hline & Frequency & $\mathrm{N}$ \\
\hline & Displacement & $1 / \mathrm{N}$ \\
\hline & Velocity & 1 \\
\hline & Acceleration / & \\
\hline & $\begin{array}{c}\text { Acceleration due } \\
\text { to gravity (g's) }\end{array}$ & $\mathrm{N}$ \\
\hline
\end{tabular}

The literature review indicates that focus of the research in this area has been on caisson type gravity walls with backfill material. Also the sizes of the prototypes investigated was rather small i.e. between 4 and $6 \mathrm{~m}$ high. The Gravity Wharf structure problem is quite different from these, as there is no soil pressure to drive the rotation of these structures. Both the open seaside and the port-side have the same level of water although the wave loading may be more severe on the open seaside. However the settlement concerns due to liquefiable soils below the Gravity Wharf structure is similar to that in 
the case of caisson gravity wall. In fact, at many locations replacement of the foundation soil below the Gravity Wharf structure with denser material is sought just like the caisson gravity wall, with accompanied cost implications of carrying out ground improvement below seabed. One of the objectives of this study is to investigate the magnitude of settlements without attempting any ground improvement. In this study the centrifuge testing was done aboard the $10 \mathrm{~m}$ diameter Turner beam centrifuge at Cambridge and the servo-hydraulic earthquake actuator (Madabhushi et al, 2012) was used create various, predetermined earthquake loadings. The biggest challenge in carrying out dynamic centrifuge modelling of the Gravity Wharf Structures was their size. At prototype scale these are about $25 \mathrm{~m}$ high above the seabed as discussed earlier. In order to create a reasonable model of these structures at the laboratory scale, they need to be tested at a very high gravity level. The tests reported in this paper were carried out at 80 g's (i.e. $80 \times$ earth's gravity), which is the highest design $\mathrm{g}$ level for the safe operation of the servo-hydraulic shaker at Cambridge.

\subsection{Centrifuge model of the Gravity Wharf Structure}

A centrifuge model was fabricated using $6.25 \mathrm{~mm}$ thick Aluminium alloy plates to represent a prototype wharf structure at $80 \mathrm{~g}$ 's. The dimensions of the centrifuge model were $313 \mathrm{~mm} \times 369 \mathrm{~mm}$ and it represents a prototype wharf structure of $25.04 \mathrm{~m} \times 29.52 \mathrm{~m}$. The bearing pressure applied by such a prototype would be high as discussed earlier. So the model wharf structure was filled with Hostun sand so that at $80 \mathrm{~g}$ the model structure applies a bearing pressure of $471.0 \mathrm{kPa}$ on the foundation soil. Further the wharf structures are normally placed on a levelled seabed over which free draining material such as gravel is placed and levelled. This aspect was modelled by using a higher permeability Fraction B sand at the base of the model wharf structure as shown in Fig. 2. The properties of the two sands used are presented in Table 2. It must be pointed out that this model structure assumes plane strain conditions, which are appropriate for this problem as the real Gravity Wharf structures are very long compared to their height and width as described in the introduction.
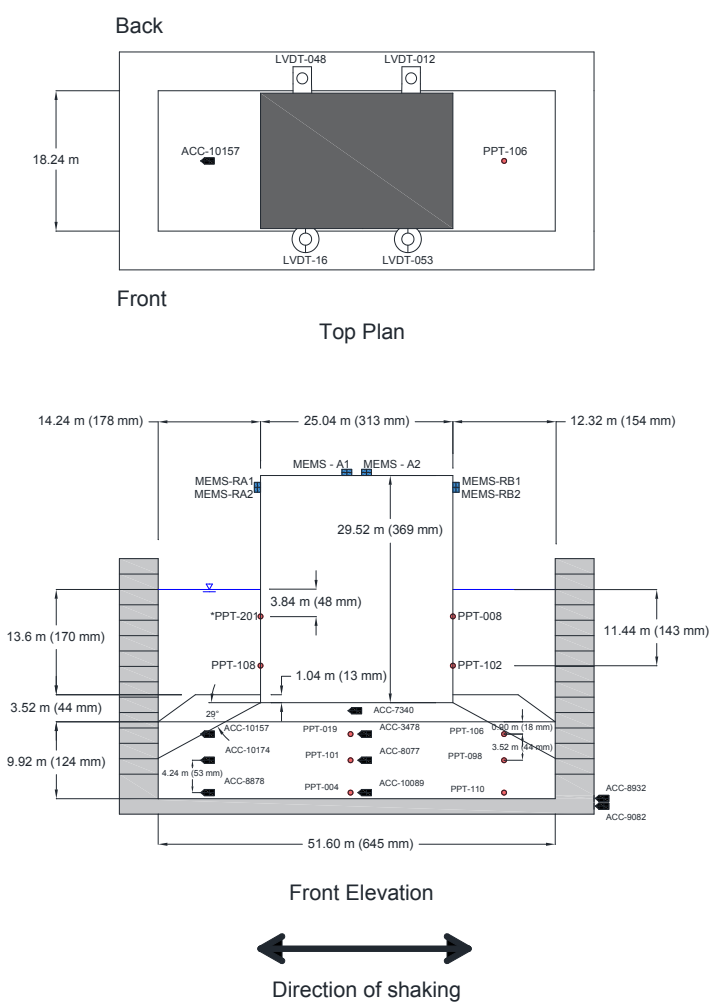

Figure 2: Instrumentation layout in the centrifuge model of a Gravity Wharf Structure 
The centrifuge model was constructed by air-pluviating dry Hostun sand using the automatic sand pourer (Madabhushi et al, 2006) to a depth of $124 \mathrm{~mm}$ ( $9.92 \mathrm{~m}$ at prototype scale). This layer was placed at a relative density of $58 \%$ as medium dense sand layer so that it will be susceptible to liquefaction but not excessively so. The bearing layer that is free draining was chosen to be Fraction $\mathrm{B}$ sand and this layer was then air-pluviated to a depth of $31 \mathrm{~mm}$ ( $2.48 \mathrm{~m}$ at prototype scale). Once this layer was in place, the centrifuge model was saturated using high viscosity fluid to form the pore fluid to satisfy the scaling laws for time given in Table 1 during excess pore pressure generation from dynamic loading and dissipation during the reconsolidation processes. More details of this procedure can be found in Madabhushi (2014). Methyl cellulose was prepared at a viscosity of $80 \mathrm{cSt}$ and the soil model was saturated using the Cam-Sat computer-controlled saturation system (Stringer and Madabhushi, 2009). This procedure involves de-airing the dry soil thoroughly and flushing with $\mathrm{CO}_{2}$ gas for a few cycles to ensure good saturation of the soil model. The Fraction B coarse sand that represents the rubble mound was then placed to a depth of $31 \mathrm{~mm}$ ( $2.48 \mathrm{~m}$ at prototype scale). The model Gravity Wharf structure was then placed on the Fraction B sand layer as shown in Fig. 2. The inside of this structure was filled by removing the top plate and filled with the bulk material (Fraction $B$ sand) to the required level so that at $80 \mathrm{~g}$ 's it applies a bearing pressure of $471 \mathrm{kPa}$. The top plate was then secured back with screws and instrumentation was attached to the top plate.

Table 2: Soil properties

\begin{tabular}{lccccc}
\hline & $e_{\max }$ & $e_{\min }$ & $\begin{array}{c}\text { Dry density } \rho_{d} \\
\left(\mathrm{~kg} / \mathrm{m}^{3}\right)\end{array}$ & $\begin{array}{c}\text { Permeability } \\
\mathrm{k}(\mathrm{m} / \mathrm{s})\end{array}$ & $\begin{array}{c}\text { Specific } \\
\text { Gravity } \mathrm{G}_{\mathrm{s}}\end{array}$ \\
\hline Hostun Sand $^{*}$ & 0.648 & 1.041 & 1541 & $1 \times 10^{-3}$ & 2.65 \\
\hline Fraction B $^{+}$ & 0.486 & 0.78 & 1558 & $7 \times 10^{-3}$ & 2.65 \\
\hline
\end{tabular}

*after Haigh et al (2012) \& Brennan (2004)

+after Tan (1990)

\subsection{Instrumentation used on the centrifuge model}

One of the advantages of dynamic centrifuge modelling is that the models can be instrumented and the performance of the gravity wharf structure can be observed prior to, during and after the earthquake loading. The instrumentation used and their locations within the centrifuge model are shown in Fig. 2. Miniature Piezo-accelerometers were used within the soil body. MEMS accelerometers were used to measure the horizontal and vertical accelerations on the model gravity wharf structure. In addition four LVDT's were fixed to the model wharf structure and its settlement relative to the centrifuge model container were measured. The locations of these four LVDT's is shown in the plan view in Fig. 2. In addition to this the excess pore pressures generated during the earthquake loading were measured at 3 locations below the model wharf structure and also at 3 locations in the free field as seen in Fig. 2.

\subsection{Earthquake motions}

During the centrifuge testing of the model wharf structures described in this paper, five different earthquake motions were used. These are listed in Table 3. The usual design concern while designing these gravity wharf structures located on liquefiable soil deposits is the magnitude of settlement they will suffer under different earthquake loading. Normally it is desirable that during a small magnitude earthquake with a short return period, the wharf structure does not accumulate too much settlement and should remain operational. During a medium magnitude earthquake the wharf structure can sustain damage but must be repairable, while during a strong magnitude earthquake with a long 
return period of 475 years or so, excess damage in the form of excessive settlements and rotation are expected.

Accordingly in this research, the first three earthquakes considered are sinusoidal earthquakes of increasing magnitude. The fourth earthquake is a realistic earthquake motion that was scaled based on Kobe earthquake motion. The fifth earthquake is a scaled version of the Imperial Valley earthquake motion. All earthquakes were fired using the servo-hydraulic earthquake actuator. The realistic earthquake motions were scaled so that they retain the same frequency content but the peak accelerations are smaller.

Table 3: Input motion characteristics

\begin{tabular}{|l|c|c|c|c|c|c|}
\hline \multirow{1}{*}{$\begin{array}{c}\text { Model } \\
\text { earthquake id. }\end{array}$} & \multicolumn{2}{c|}{$\begin{array}{c}\text { Peak bedrock } \\
\text { acceleration }(\mathrm{g})\end{array}$} & \multicolumn{2}{c|}{$\begin{array}{c}\text { Duration } \\
(\mathrm{s})\end{array}$} & \multicolumn{2}{c|}{$\begin{array}{c}\text { Predominant } \\
\text { Frequency }(\mathrm{Hz})\end{array}$} \\
\cline { 2 - 7 } & Prototype & Model & Prototype & Model & Prototype & Model \\
\hline EQ1 & 0.05 & 4.0 & 10 & 0.125 & 1 & 80 \\
\hline EQ2 & 0.19 & 15.2 & 10 & 0.125 & 1 & 80 \\
\hline EQ3 & 0.29 & 23.2 & 10 & 0.125 & 1 & 80 \\
\hline $\begin{array}{l}\text { EQ4 - Kobe } \\
\text { motion }\end{array}$ & 0.18 & 14.4 & 16 & 0.200 & $0 \sim 2.6$ & $0 \sim 208$ \\
\hline $\begin{array}{l}\text { EQ5 - Imperial } \\
\text { Valley motion }\end{array}$ & 0.12 & 9.6 & 60 & 0.750 & $0 \sim 4.75$ & $0 \sim 380$ \\
\hline
\end{tabular}

The accelerations measured during each of these earthquakes at the base of the centrifuge model container are presented in Fig. 3. These would be the bedrock accelerations in the prototype case as indicated in Fig.1. The Imperial Valley motion is a high frequency, long duration earthquake and as a result it is plotted to a different time scale of $70 \mathrm{~s}$, while all other motions are shown up to $30 \mathrm{~s}$.

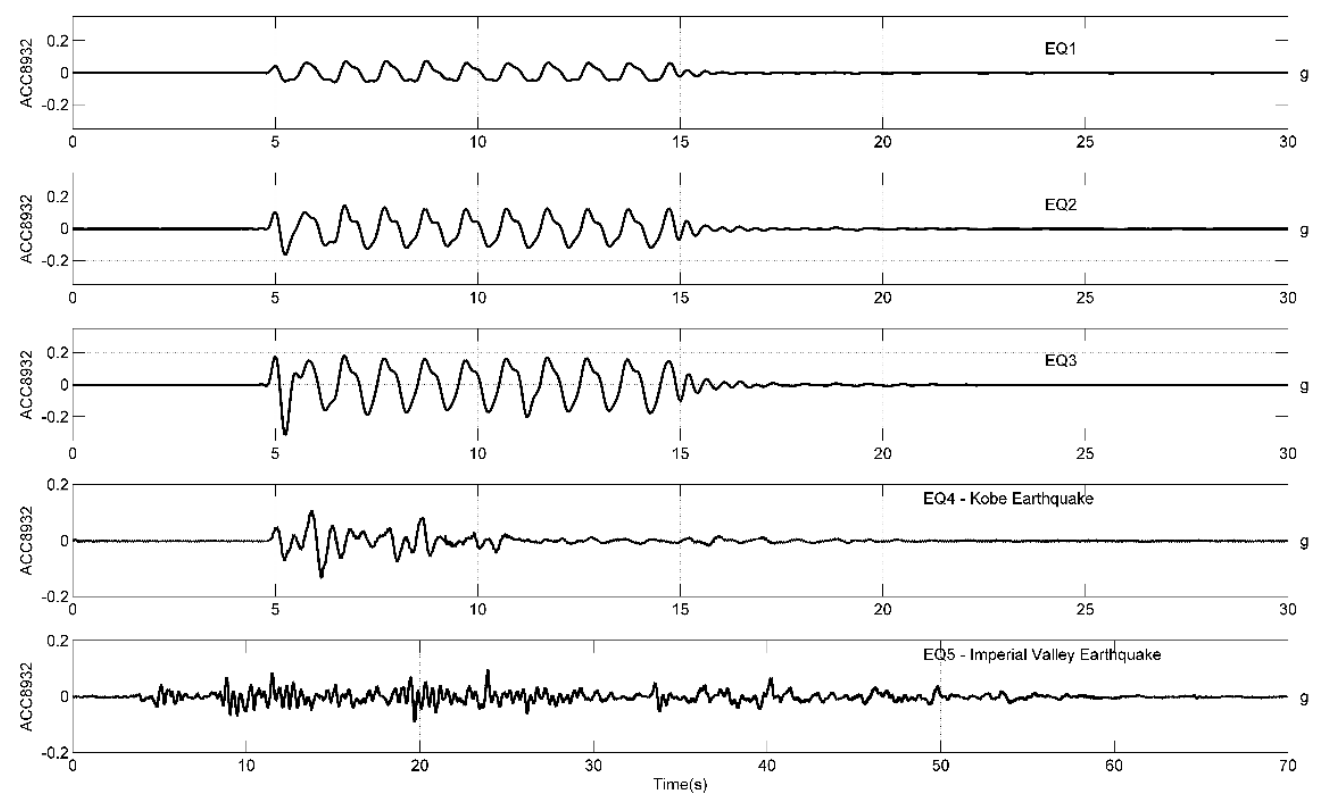

Figure 3: Input motions 


\section{Dynamic Response of the Gravity Wharf Structure}

The dynamic response of the Gravity Wharf Structure is of interest from a structural integrity point of view and the accelerations subjected to the dockside structures, like cranes, warehouses etc. In this section the acceleration response of the Gravity Wharf Structure will be presented for various earthquakes applied. In addition, the hydro-dynamic pressures generated on the open seaside and on the port-side will also be presented.

\subsection{Acceleration response of the Gravity Wharf Structure}

The accelerations were measured at the top of the Gravity Wharf structure by mems accelerometer A1. For the strongest of the earthquakes (EQ3, shown in Fig.3), this is presented in Fig. 4a. There is a modest amplification of the accelerations between the rubble mound and the top of the structure, especially in the later cycles as seen in this figure. However, the higher harmonics die down completely and the accelerations felt at the top of the structure contain more or less a single frequency. This suggests that damping in the structure, especially with Fraction B as the bulk fill material within it, damps out the high frequency components. The vertical accelerations measured on either side of the Gravity Wharf structure by RA1 and RB1 are also shown in Fig. 4a. These do contain the higher frequency components to some extent. More interestingly there is a significant phase lag between the RA1 and RB1 traces in this figure, especially during the later cycles. This clearly confirms that the Gravity Wharf structure suffers from rocking vibrations. This is to be expected given the high centre of gravity of these structures, which also contributes to the increased horizontal accelerations at the top of these structures. Similar behaviour was observed in all the other sinusoidal earthquakes (EQ1 and EQ2) although these are not shown here for brevity.

It is interesting to consider one of the realistic earthquake motions here. For the case of EQ5, the scaled Imperial Valley motion (shown in Fig.3), the time histories recorded by A1, RA1 and RB1 are presented in Fig. 4b. This is a very long motion of nearly $60 \mathrm{~s}$ with high frequency components. Referring to Fig. $4 \mathrm{~b}$ it can be seen that there is significant amplification of horizontal accelerations recorded by A1. The vertical accelerations recorded by RA1 and RB1 are smaller, although they still show the phase lag suggesting rocking of the structure as before.
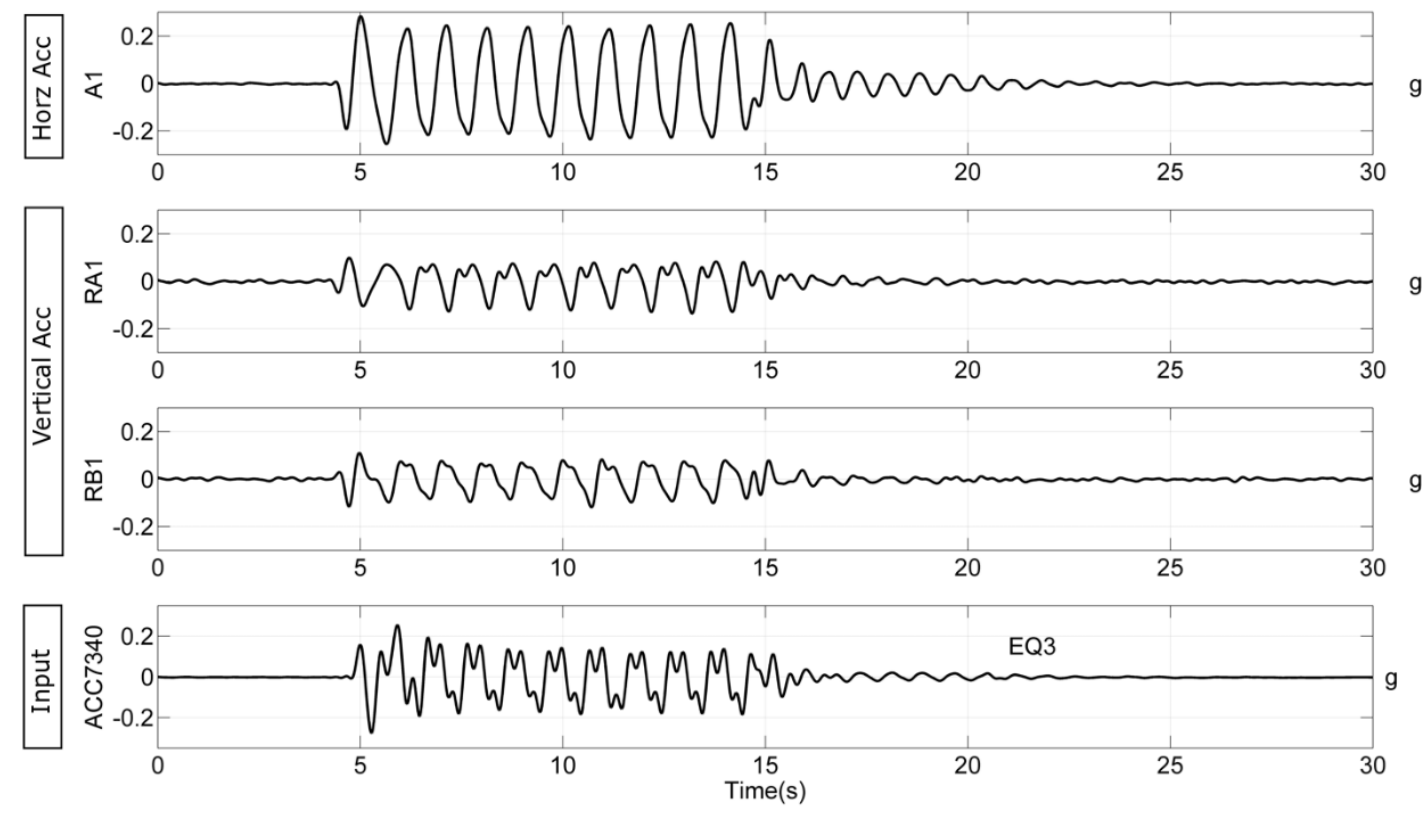

Figure 4a: Response to a strong, sinusoidal input motion 

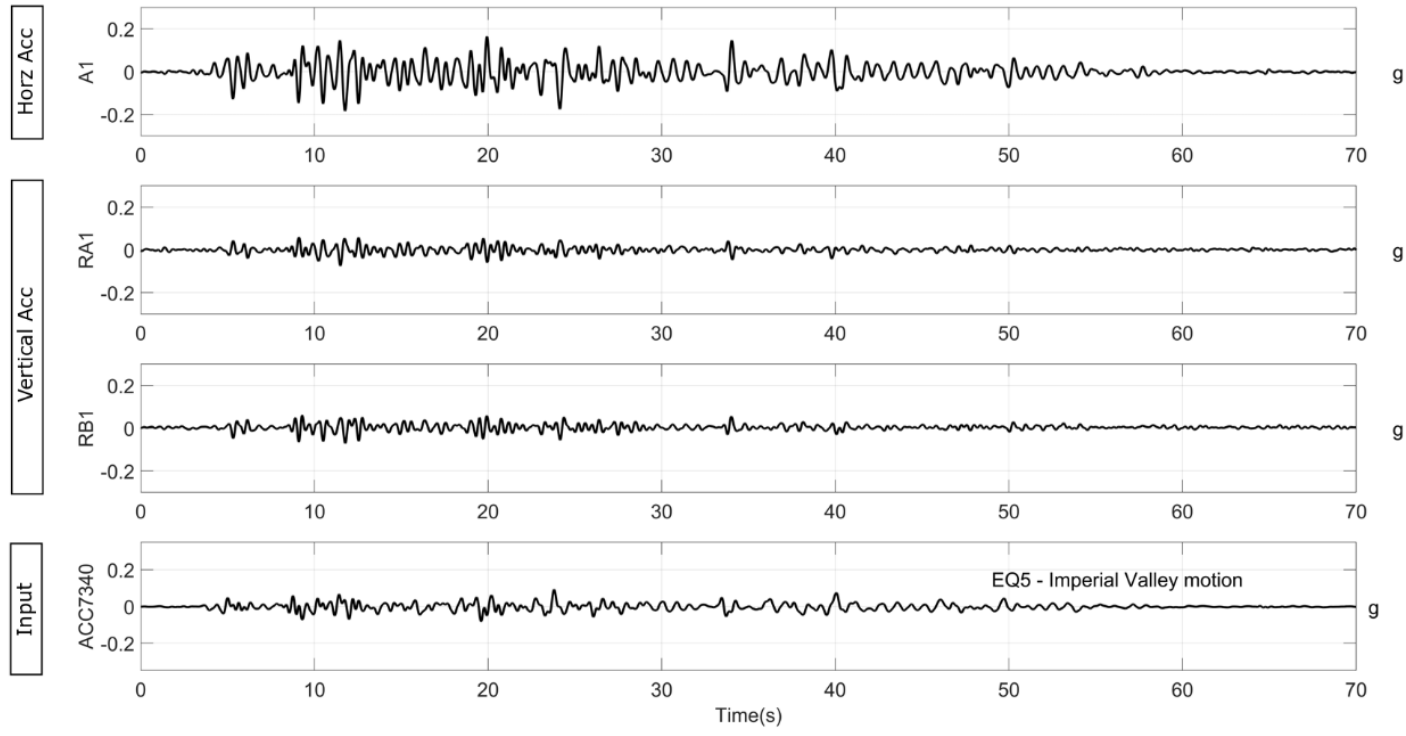

Figure 4b: Response to the Imperial Valley motion

In order to investigate the amplifications observed in this multi-frequency realistic motion, discrete Fast Fourier Transforms (FFT) were calculated for the time-history recorded by A1 and presented in Fig. 5. For comparison the FFT of the input motion is also shown in this figure. In this figure it can be seen that the components below $1.6 \mathrm{~Hz}$ are amplified significantly within the Gravity Wharf structure. In contrast the components above $1.6 \mathrm{~Hz}$ are only amplified marginally. In fact although there is a component in the input motion at $4.9 \mathrm{~Hz}$, this is completely attenuated in the structure. This suggests that model Gravity Wharf structure damps out the higher frequencies very well, but is not able to do so for lower frequency components. This may be due to the frequency dependent damping characteristics of the bulk material within the structure.

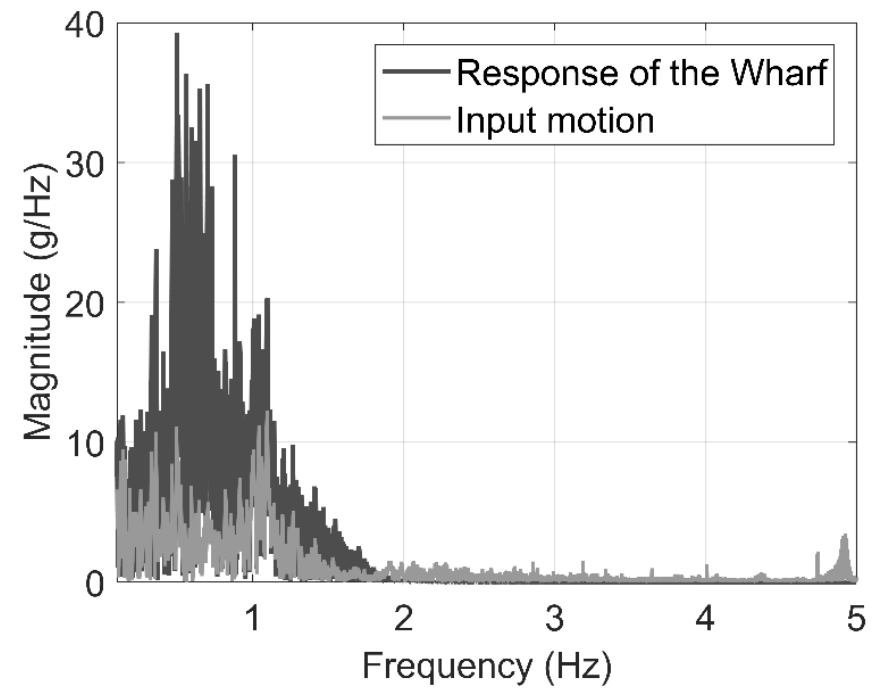

Figure 5: Frequency response of the Gravity Wharf Structure

\subsection{Hydro-dynamic pressures}

Another important aspect in terms of loading on the Gravity Wharf Structures is the hydro-dynamic pressures generated by the earthquake loading. During the design process for these structures, the approximate equation proposed by Westergaard (1933) is widely used. This approximate parabolic 
equation is for comparison with experimental data and assumes the width of water body extending to infinity.

The hydro-dynamic pressure $p_{o}$ can be evaluated using equation (1) shown below:

$$
p_{o}=\frac{7}{8} \gamma_{w} \alpha \sqrt{H y}
$$

where $\gamma_{w}$ is the unit weight of water, $\alpha$ is the horizontal acceleration, $H$ is the total water depth and $y$ is the location below water surface where $p_{o}$ is evaluated. For cases where the water body has a limited width, as is the case in these experiments, Brahtz \& Heilbron (1933) suggested correction factors based on the height of the gravity wharf structure and the width of the water body. Similarly Housner (1954) suggested a procedure to evaluate hydro-dynamic pressures for fluids in containers subjected to earthquake loading.

This research provides an opportunity to measure the hydro-dynamic pressures directly during the centrifuge testing. These were measured using 4 PPT's on either side of the model structure as shown in Fig. 2. It must be pointed out that it would have been better to have included much denser instrumentation, however, the measurement of these hydro-dynamic pressures was not the main emphasis of this research. Also there was a slightly lower water level $(15 \mathrm{~mm}$ less i.e. a drop of $1.2 \mathrm{~m}$ of the sea level at prototype scale) in the test where EQ3 was fired. Notwithstanding this, it is possible to make some interesting observations from the experimental data.

In Fig. 6a the hydro-dynamic pressures measured during a small earthquake (EQ1) are presented. The top two traces show the measurements at the shallow depth ( $3.8 \mathrm{~m}$ below water surface), while the next two traces show the same at the deeper level (11.4 m below water surface). As seen in Fig. 6a, during this earthquake the hydro-dynamic pressures are larger at the deeper level than at the shallow level, as expected. It is also seen clearly that the hydro-dynamic pressures on either side of the model structure are out-of-phase. This suggests that the hydro-dynamic loading will be additive on the structure from pressures on either side. In Fig. $6 \mathrm{~b}$ similar traces for the case of the strong earthquake (EQ3) for the deeper level are presented. The magnitude of the hydro-dynamic pressures is larger than those observed in EQ1. However, the increase in magnitude of these hydro-dynamic pressures appears to be small, although the earthquake magnitude has increased from $0.05 \mathrm{~g}$ to $0.29 \mathrm{~g}$. The magnitude of the hydro-dynamic pressures only increased from about $8 \mathrm{kPa}$ to $14 \mathrm{kPa}$ between these two earthquakes. It must be pointed out that there are space limitations in a centrifuge model due to the size of the model container and consequently the water reservoirs encounter boundaries both on the seaside and the port-side. Also the side walls of the model container form an Equivalent Shear Beam (ESB) to minimise the stress wave reflections in the soil by deforming the same way as the soil does, under dynamic loading. These deflections and limited space may have an influence on the magnitude of the hydro-dynamic pressures. Subject to these limitations these pressures can be compared qualitatively to the Westergaard (1933) equation. Similarly the experimental hydrodynamic pressures can be compared to the values obtained using the corrected procedure suggested by Brahtz \& Heilbron (1933) and to the procedure suggested by Housner (1954). 


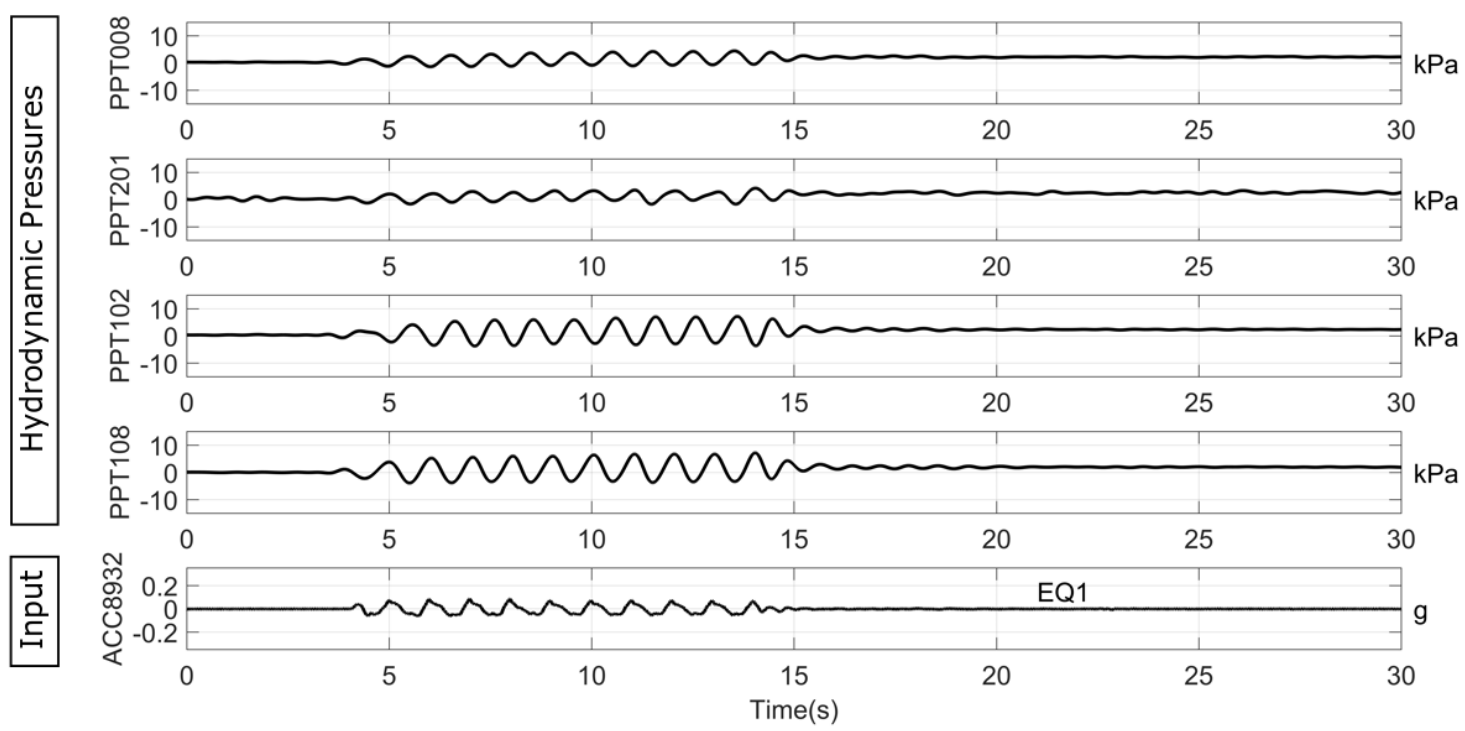

Figure 6a: Hydro-dynamic pressures generated during a small earthquake
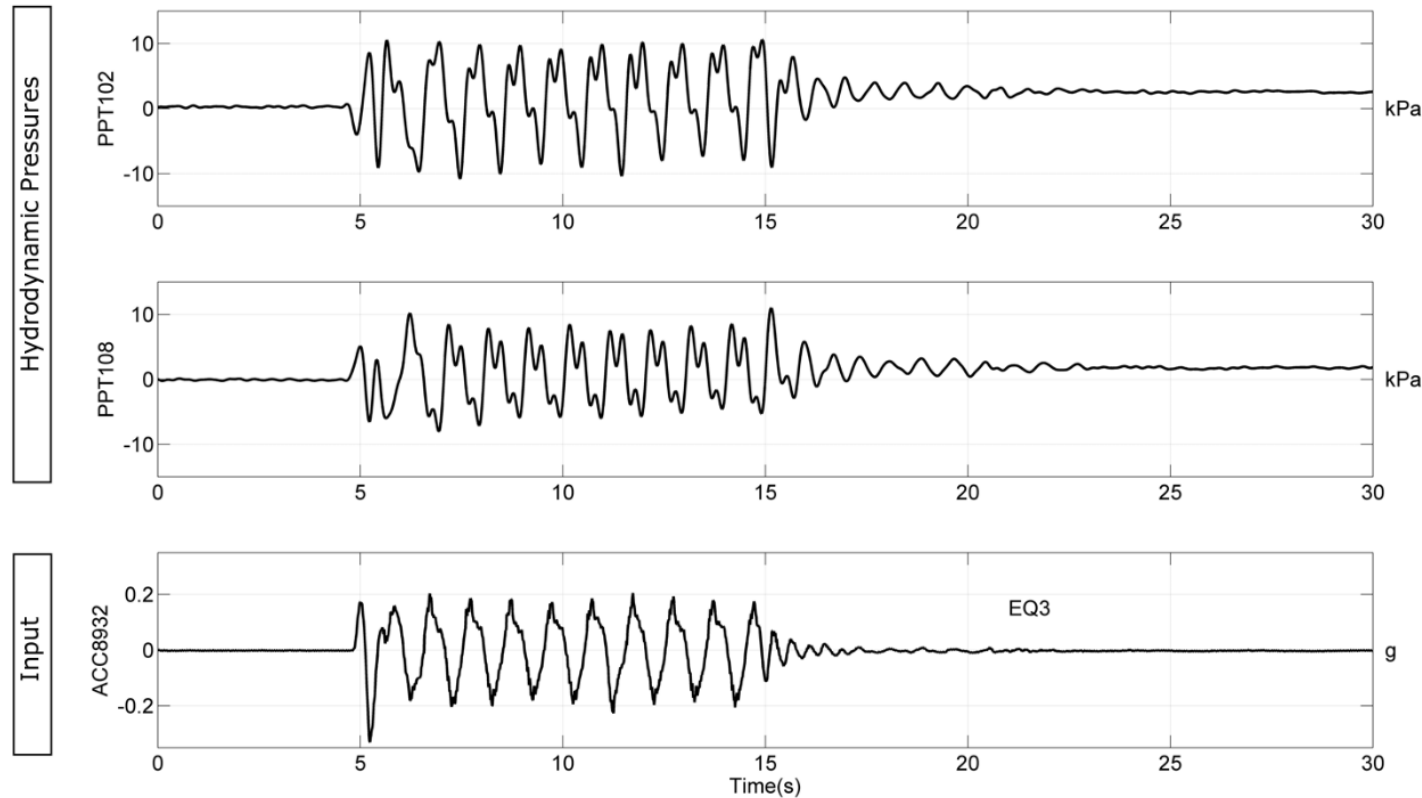

Figure 6b: Hydro-dynamic pressures generated during a strong earthquake

The theoretical hydro-dynamic pressures for the first three earthquakes were evaluated using Eq. 1 above and presented in Fig. 7. In this figure the experimentally observed hydro-dynamic pressures were also plotted at the two depths where these were measured, in each of these earthquakes. A parabola was fitted to pass through the experimental data points shown as dashed lines in Fig. 7 for each of the earthquakes. The drop in water level for EQ3 was accounted for in the theoretical calculations. For the case of the small earthquake (EQ1), it appears that the Westergaard's equation under predicts the hydro-dynamic pressures. Brahtz \& Heilbron (1933) correction for EQ1 brings it closer to the experimental value slightly as does the use of Housner (1954) procedure. For the stronger earthquakes (EQ2 and EQ3) the Westergaard's equation appears to over-predict the hydro-dynamic pressures compared to the experimental results. Brahtz \& Heilbron (1933) corrections for EQ2 and EQ3 take predictions further away as seen Fig. 7. Using the Housner (1954) procedure also overpredicts the hydro-dynamic pressures significantly compared to the experimentally observed values. Similar observations were made by Saleh and Madabhushi (2010a, b) with respect to Westergaard's 
equation, who investigated the hydro-dynamic pressures behind rigid and flexible dams under earthquake loading. It must be pointed out the drop in reservoir level of $1.2 \mathrm{~m}$ during EQ3 test was accounted for while using Eq.1 and for Brahtz \& Heilbron (1933) correction and while using Housner (1954) procedure for this case. As a result Housner's procedure predicts smaller hydro-dynamic pressures at shallow depths for EQ3 compared to EQ2, and there is a cross-over point at a depth of $5.5 \mathrm{~m}$, below which the stronger EQ3 produces larger hydro-dynamic pressures.

The observations regarding hydro-dynamic pressures in this research, although limited in nature and subject to the limitation outlined above, suggest an interesting avenue for further research in which the hydro-dynamic pressures on Gravity Wharf structures can be evaluated more fully and the results can benefit the design process of these structures.

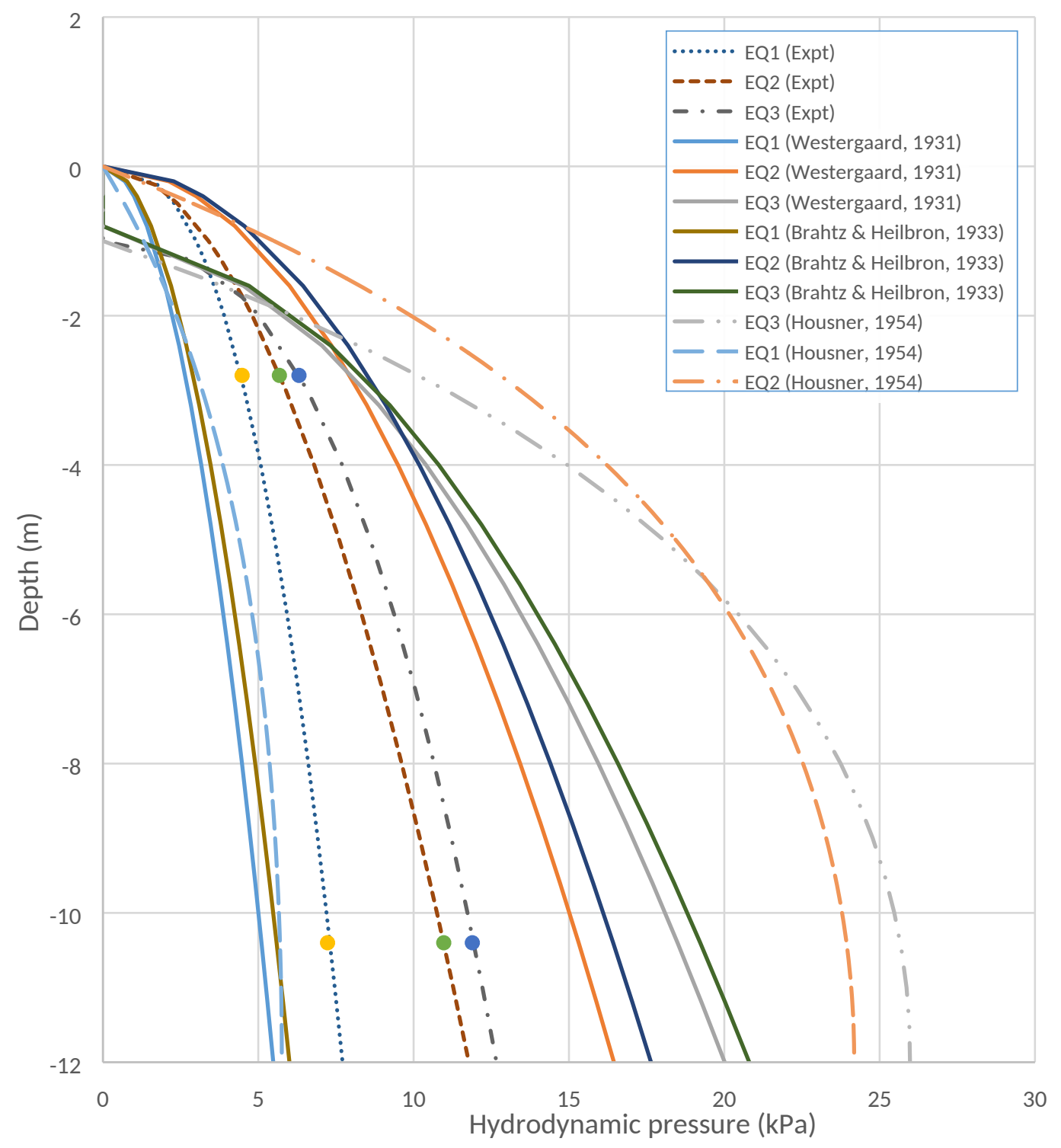

Figure 7: Comparison of experimental and theoretical hydro-dynamic pressures

\section{Excess pore water pressures in the foundation soil}

Liquefaction is said to have occurred when the total pore water pressure (hydrostatic + excess pore water pressure) reaches a value close to the total stress in the soil causing the effective stress to become nearly zero. This will cause any structure that is located on the liquefiable soil to suffer 
excessive settlements and/or rotations. In the case of Gravity Wharf Structure the total stress below is quite high due to the high bearing pressure exerted by these structure. One of the main aims of this research was to assess the settlement suffered by these structures when liquefaction occurs. To investigate this the excess pore pressures (epp) recorded by a vertical array of PPT's below the model structure are compared with an array in the notional free-field away from the structure (see Fig. 2). For the case of EQ3, the strongest of the earthquakes, these excess pore pressures are presented in Fig. 8. For the free-field excess pore pressures, the total stresses and the hydrostatic water pressures were evaluated at the depth of each instrument. Based on these the excess pore pressure required to cause full liquefaction is marked by the dotted line, which is the line where the excess pore pressure ratio ' $r r_{u}$ ' will be unity. It can be seen in Fig. 8 that full liquefaction has occurred at all the depths in the free-field, and the excess pore pressures reach the $r_{u}=1$ line. In fact, the cyclic components rise slightly above this, indicating that there is a net vertical acceleration of the soil body during the earthquake loading. Similar observations were made by Hughes and Madabhushi (2018) with respect to basement structures in liquefied soils. In contrast, the excess pore pressures below the structure are much higher at comparative depths. However, the total stress in this region is also much higher due to the $471 \mathrm{kPa}$ of bearing pressure exerted by the model Gravity Wharf structure. Thus full liquefaction did not occur in this region and any settlements that result are due to the partial softening of the soil due to a reduction in the effective stress owing to these excess pore pressures. Further, it is also interesting to see the frequency response of the excess pore pressures below the structure, which exhibit strong double frequency components. This may be due to the intense shearing of the soil in this region driven by the heavy structure on the top.
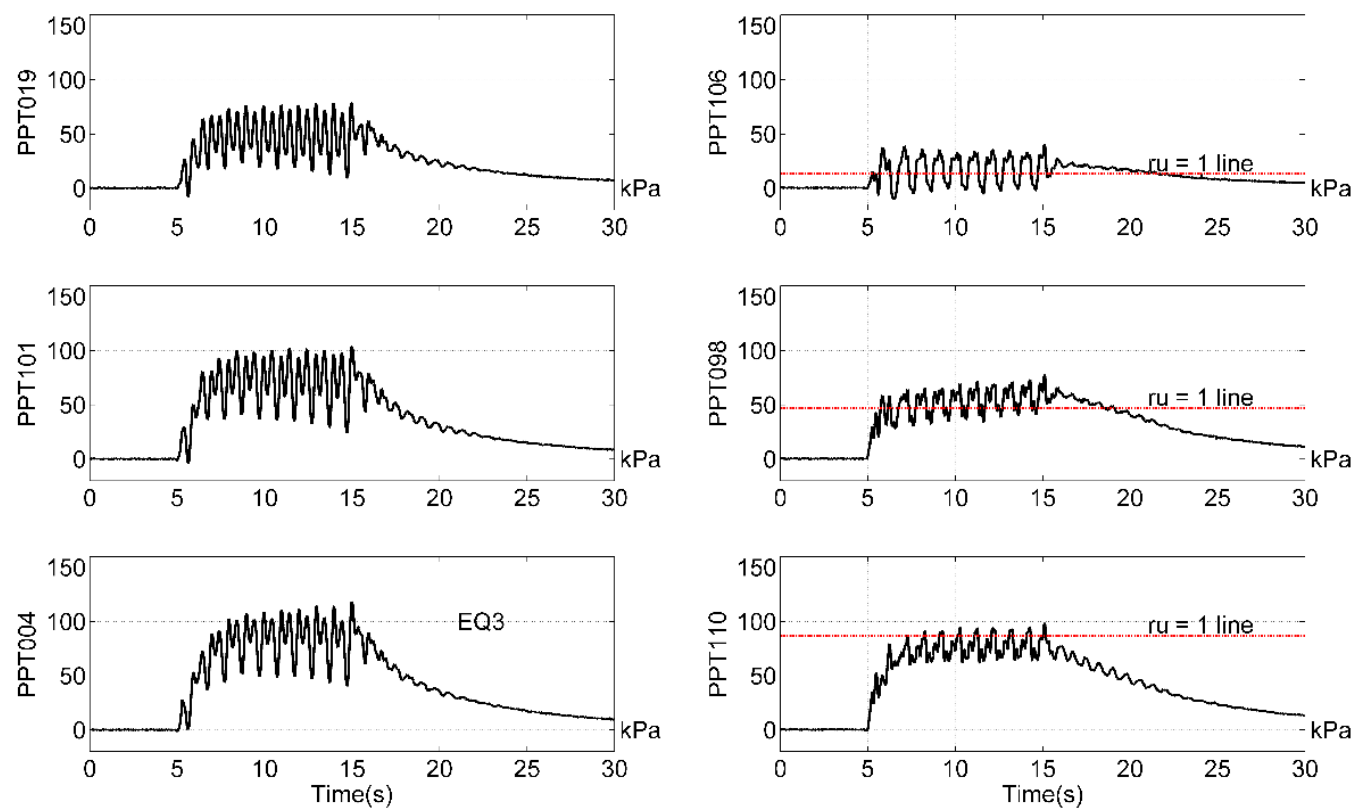

Figure 8: Excess pore pressures (epp) generated during a strong earthquake

In Table 4, the maximum excess pore pressures recorded in all five earthquakes are presented. In this table it can be seen that excess pore pressures are consistently higher below the structure compared to the free-field for all the earthquakes. Also the excess pore pressures are higher in the first three earthquakes, and increase proportional to the strength of the earthquake. A small drop in excess pore pressures are seen in EQ3 owing to some densification of the sand. Excess pore pressures recorded in 
EQ4 and EQ5 are much smaller, due to their small magnitudes (see Fig. 3). In these earthquakes, even the free-field soil did not suffer full liquefaction.

Overall, the free-field has fully liquefied in all of the larger earthquakes. The excess pore pressures generated below the structure are larger than in the free-field, but the foundation soil below the structure does not liquefy owing to the large bearing pressure exerted by the model Gravity Wharf structure.

Table 4: Excess pore pressures in all earthquakes

\begin{tabular}{|c|c|c|c|c|c|c|}
\hline & & EQ1 & EQ2 & EQ3 & EQ4 & EQ5 \\
\hline \multirow{2}{*}{$\begin{array}{c}\text { Free-Field } \\
\text { epp. } \\
(\mathrm{kPa})\end{array}$} & PPT106 & 31.7 & 39.6 & 40.2 & 17.0 & 8.5 \\
\cline { 2 - 7 } & PPT098 & 69.2 & 80.4 & 77.9 & 30.4 & 16.1 \\
\cline { 2 - 7 } & PPT110 & 101.9 & 105.4 & 98.7 & 32.6 & 18.7 \\
\hline $\begin{array}{c}\text { epp. below } \\
\text { the } \\
\begin{array}{c}\text { Structure } \\
(\mathrm{kPa})\end{array}\end{array}$ & PPT019 & 61.6 & 68.1 & 78.7 & 23.1 & 12.7 \\
\cline { 2 - 7 } & PPT101 & 91.4 & 108.3 & 103.7 & 27.2 & 16.4 \\
\hline
\end{tabular}

\section{Settlement of the Gravity Wharf Structure}

Finally, the settlements suffered by the Gravity Wharf structure under earthquake loading are considered. This is of prime importance from a design point of view and often very expensive soil replacement and other ground improvement measures are implemented with a view to minimise the settlements. Also rotations are a major concern. As reported by Satoh et al (1998), rotations are significant for caisson type gravity quay walls. However, for the Gravity Wharf structure there is no backfill material to drive the rotations, and therefore any rotations are primarily due to the asymmetry in the earthquake loading.

The settlements were recorded by four LVDT's on either side of the model structure (see Fig. 2). For the case of EQ3, these are presented in Fig. 9. In this figure we can see that settlements are in the range of 133 to $175 \mathrm{~mm}$ across all the instruments. This suggests relatively uniform settlement of the whole block. Also the cyclic components show out-of-phase between LVDT's on either side, confirming the rocking of the model Gravity Wharf structure. It is also interesting to note that almost all of the settlements occur during the earthquake loading and very little settlement occurs in the post-seismic period. The level of settlements during a strong earthquake is quite satisfactory for such a large structure. However, connections to services on the topside may have to be designed to accommodate this level of settlements. Further crane rails and other devices may have to be re-adjusted following such liquefaction induced settlements. 


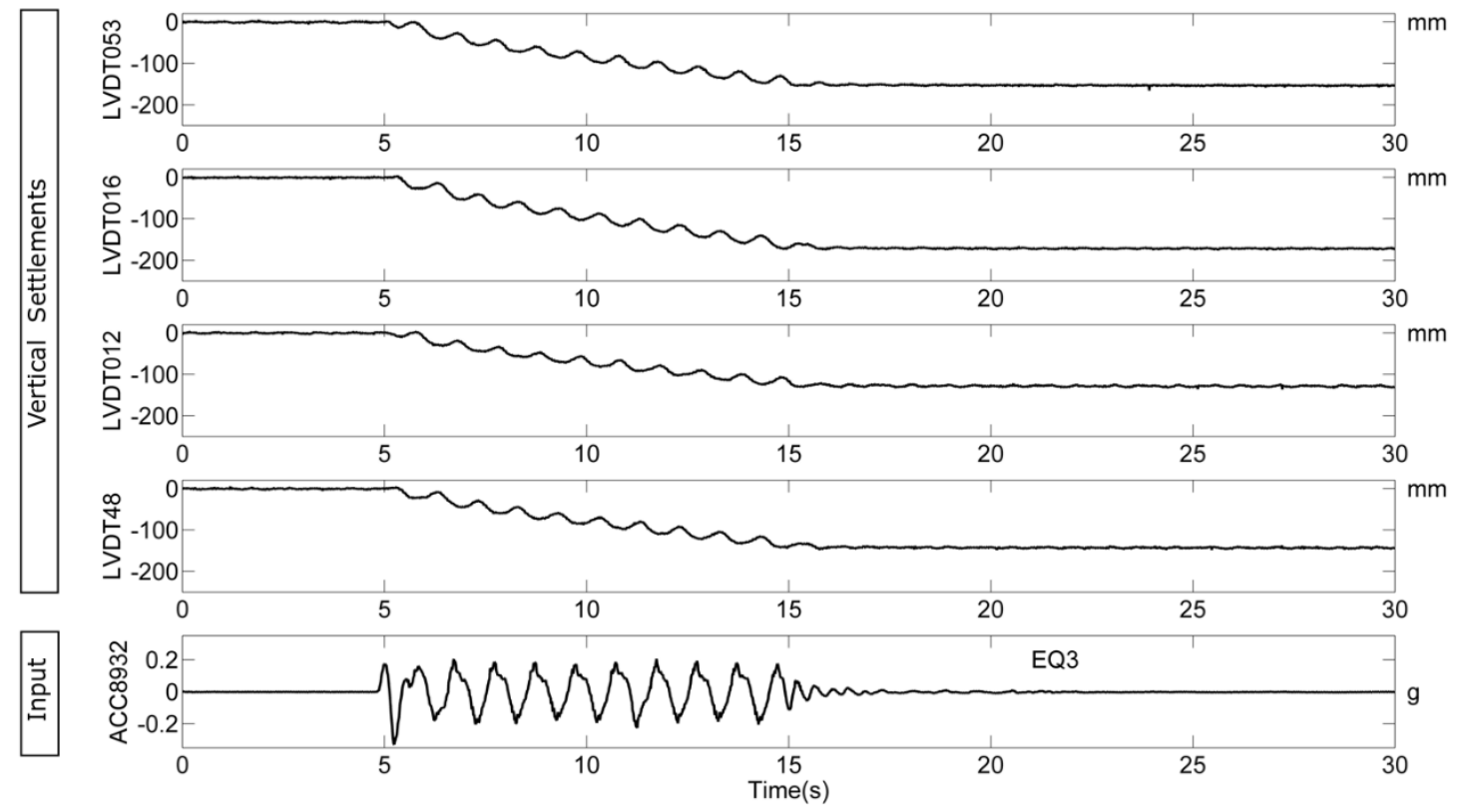

Figure 9: Settlements recorded during a strong earthquake (EQ3)

It is possible to compute from the vertical settlements, the rotations suffered by the model structure, as the distance between the LVDT's is known. For the case of EQ3, the rotations calculated using the two sets of LVDT's are presented in Fig. 10. In this figure it can be seen the cyclic amplitude of the rotations is about $1.5^{\circ}$. However, there is a small residual rotation after the earthquake loading has completed of about $0.8^{\circ}$. Such small rotations may be considered satisfactory from SLS point of view.
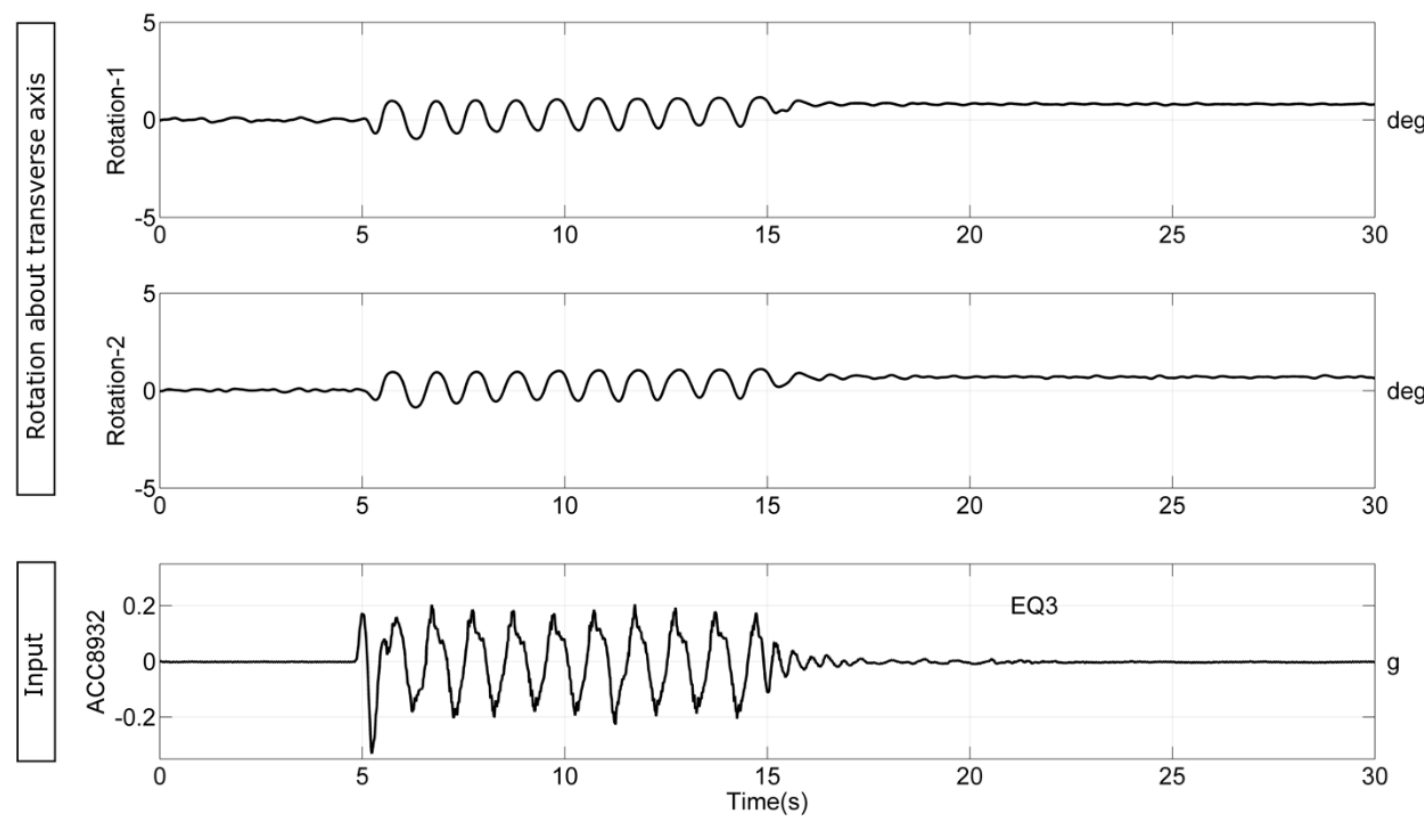

Figure 10: Rotations recorded during a strong earthquake (EQ3)

The settlements recorded in all of the earthquakes are presented in Table 5. It is interesting to note that in the first three earthquakes, the magnitude of settlements increase only marginally despite the increase in the input accelerations (see Fig. 3). Also in EQ4 and EQ5, the magnitude of settlements are very small owing to their small magnitudes. 
Table 5: Settlements in all earthquakes

\begin{tabular}{|c|c|c|c|c|c|c|}
\hline & & EQ1 & EQ2 & EQ3 & EQ4 & EQ5 \\
\hline \multirow{2}{*}{$\begin{array}{c}\text { Settlements } \\
\text { Left }(\mathrm{m})\end{array}$} & LVDT053 & 0.132 & 0.150 & 0.156 & 0.018 & 0.009 \\
\cline { 2 - 7 } & LVDT016 & 0.154 & 0.174 & 0.175 & 0.020 & 0.008 \\
\hline $\begin{array}{c}\text { Settlements } \\
\text { Right }(\mathrm{m})\end{array}$ & LVDT012 & 0.132 & 0.139 & 0.133 & 0.013 & 0.008 \\
\cline { 2 - 7 } & LVDT48 & 0.151 & 0.157 & 0.148 & 0.017 & 0.009 \\
\hline
\end{tabular}

\section{Conclusions}

The Gravity Wharf Structures are gaining popularity owing to their ease of construction in dry docks and deployment to the site. However, where the site conditions consist of loose to medium dense sands, liquefaction risks exist and often this is mitigated by expensive soil replacement or soil improvement techniques. In this paper a model Gravity Wharf Structure was investigated using dynamic centrifuge testing. Several strong bedrock motions were applied to the model in-flight, which included sinusoidal motions and scaled versions of Kobe earthquake and Imperial Valley earthquake motions. The experimental work described here has some limitations with respect to the size of the model container and the proximity of the lateral boundaries. Further developments on larger model containers are currently underway to facilitate testing of models of large prototype structures.

The behaviour of the model structure under these earthquakes was investigated in terms of the dynamic response of the structure, hydro-dynamic pore water pressures and settlements. The structure showed marginal amplifications during the $1 \mathrm{~Hz}$, sinusoidal motions. However, the Imperial Valley earthquake caused significant amplifications particularly in the low frequency range, while higher frequencies were attenuated. This may be ascribed to the damping of higher frequencies by the fill material used within the Gravity Wharf Structure. The hydro-dynamic pressures measured in the experiment were compared to the approximate solution proposed by Westergaard (1933) that is widely used by the industry. Based on limited results from this research it was observed that the Westergaard's solution under-estimates the hydro-dynamic pressures for low amplitude earthquakes, while it over-estimates for stronger earthquakes. This aspect needs to be investigated more thoroughly so that gains can be made in design of these structures with better methods to estimate the hydro-dynamic pressures.

The excess pore pressures generated in the soil directly below the model structure and in the notional free-field are also presented. While full liquefaction of the soil occurred in the free-field, the foundation soil below the structure did not suffer full liquefaction. This is primarily due to the large bearing pressure exerted by the heavy Gravity Wharf structure. However, the excess pore pressures generated below the structure were consistently higher than in the free-field. This would result in some degradation in the stiffness of sand and a consequent settlement of the structure. Experimental data from centrifuge testing shows that the settlements are of the order $0.15 \mathrm{~m}$ for the sinusoidal earthquakes. The settlements increase only modestly with the increase in the magnitude of the earthquakes. The level of settlements may be acceptable from a SLS view point with some repair work needed to the topside structures in the post-earthquake period. The dynamic rotations and the residual rotations were also observed to be small for the earthquakes studied in this research.

\section{Acknowledgements}

The authors would like to acknowledge the support of all the technical staff at the Schofield Centre who facilitated the experimental testing. In addition the discussions with Mr Stephen L West, Director, Ramboll, UK and his ground engineering team Mr Ross Adams, Mr Niko Karamichalis and Mr Yasir Khokher, who inspired this work, are gratefully acknowledged. 


\section{REFERENCES}

1. Acosta, E.A., Tibana, S., Almeida, M. and Saboya, F., 2017, Centrifuge modelling of hydroplaning in submarine slopes, Ocean Engineering, 129, pp. 451-458.

2. Brahtz, J.H.A. and Heilbron, C.H., 1933, Discussion on "Water Pressures on dams during earthquakes" by H.M. Westergaard. Transactions, American Society of Civil Engineers (ASCE), Vol. 98, Paper No. 1835, New York City, NY, pp. 452-454.

3. Brennan, A. J., 2004, Vertical drains as a countermeasure to earthquake-induced soil liquefaction, $\mathrm{PhD}$ thesis, Univ. of Cambridge, UK.

4. Fujiwara, T., Horikoshi, K. and Sueoka, T., 1998, Dynamic behaviour of gravity type quay wall and surrounding soil during earthquake, Proc. Centrifuge 98, pp. 359-364, Balkema, Rotterdam.

5. Haigh, S. K., Eadington, J. and Madabhushi, S. P. G., 2012, Permeability and stiffness of sands at very low effective stresses, Géotechnique, 62(1), pp. 69-78.

6. Housner, G.W., 1954, Earthquake Pressures on Fluid Containers. Eight Technical Report under Office of Naval Research, California Institute of Technology, Pasadena, CA, pp. 1-13.

7. Hughes, F.E. and Madabhushi, S.P.G., 2018, The importance of vertical accelerations in liquefied soils, Proc. Physical modelling in Geotechnics, ICPMG 2018, CRC Press, Boca Raton, Florida, USA, pp. 967-973.

8. Inagaki, H., lai, S., Sugano, T., Yamazaki, H. and Inatomi, T., 1996, Performance of caisson type quay walls at Kobe Port, Soils and Foundations, Special issue on Geotechnical Aspects of the January 17, 1995 Hyogoken-Nambu Earthquake, Vol. 36, pp. 119-136.

9. Kamon, M., Mimura, M., Matsuda, S., Nagayama, S., Misaki, S., 1998, Experimental studies on the seismic response of a gravity caisson quay wall, Proc. Centrifuge 98, pp. 333-338, Balkema, Rotterdam.

10. Kawai, T., Kanatani, M., Tanaka, Y., Stewart, D.P., Kutter, B.L., Settgast, R.R., Ishikawa, H., Takeda, T., Higuchi, S. and Goto, Y., 1998, Seismic performance of a caisson type seawall with an armoured embankment, Proc. Centrifuge 98, pp. 351-358, Balkema, Rotterdam.

11. Madabhushi, S.P.G., 2014, Centrifuge modelling for Civil Engineers, CRC Press, Boca Raton, Florida, USA.

12. Madabhushi, S.P.G., Haigh, S.K. and Houghton, N.E., 2006, A new automated sand pourer for model preparation at University of Cambridge, Proc. International Conference on Physical Modelling in Geotechnics Centrifuge'06, pp. 217-222, Taylor \& Francis, London.

13. Madabhushi, S.P.G., Haigh, S.K., Houghton, N.E. and Gould, E., 2012, Development of a servo-hydraulic earthquake actuator for the Cambridge Turner Beam Centrifuge, International Journal of Physical Modelling in Geotechnics, Vol. 12, No.2, pp. 77-88.

14. Saleh, S. and Madabhushi, S.P.G., 2010a, Hydrodynamic pressures behind flexible and rigid dams, Dams \& Reservoirs Journal, Vol. 20, No.2, pp 73-82, Institution of Civil Engineers, UK.

15. Saleh, S. and Madabhushi, S.P.G., 2010b, An investigation into the seismic behaviour of dams using dynamic centrifuge modelling, Bulletin of Earthquake Engineering, Vol. 8, pp 1479-1495.

16. Satoh, T., Tsurugasaki, K., Nagata, T. and Miyake, M., 1998, Deformation of caisson type quay wall during earthquake, Proc. Centrifuge 98, pp. 339-344, Balkema, Rotterdam.

17. Stringer, M.E. and Madabhushi, S.P.G., 2009, Novel computer controlled saturation of dynamic centrifuge models using high viscosity fluids, ASTM Geotechnical Testing Journal, Vol. 32, Issue 6, pp 53-59.

18. Tan, F. S. C. 1990, Centrifuge and theoretical modelling of conical footings on sand, Ph. D thesis, University of Cambridge, UK.

19. Qi, G.W., Gao, F.P., Randolph, M.F. and Lehane, B.M., 2016, Scour effects on p-y curves for shallowly embedded piles in sand, Geotechnique, 66(8), pp. 648-660.

20. Westergaard, H.M., 1933, Water Pressures on Dams during Earthquakes, Trans. ASCE, Vol.98, pp. 434-436. 